\title{
Brand Equity Um estudo sobre a marca Apple
}

\author{
Gabriel Weiss de Faria \\ Trabalho de Conclusão de Curso
}

Centro de CIÊnCIAS SOCIAIS - CCS

DEPARTAMENTO dE AdMINISTRAÇÃo

Graduação em Administração de Empresas 


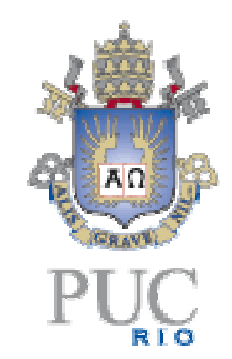

Gabriel Weiss de Faria

\section{Brand Equity Um estudo sobre a marca Apple}

Trabalho de Conclusão de Curso

Trabalho de Conclusão de Curso, apresentado ao programa de graduação em Administração da PUC-Rio como requisito parcial para a obtenção do titulo de graduação em Administração.

Orientador(a) : Sylvia Moraes

Rio de Janeiro 


\section{Agradecimentos}

A PUC-RIO pela oportunidade de que me foi dada.

A Profa ${ }^{a}$. Sylvia Therezinha Almeida de Moraes por aceitar este desafio de última hora e pelo profissionalismo sempre estando presente, me ajudando a finalizar este projeto.

Em especial a minha avó Steffi Weiss quem tornou possível a realização deste objetivo.

A meus pais Lydia e Mario quem mesmo diante de adversidades me deram o suporte necessário para nunca desistir.

A minha irmã Vanessa quem sempre me deu força nos momentos de dificuldade.

A meu amor Renata, pelo apoio, cumplicidade e carinho ao longo desta jornada. 


\section{Resumo}

Weiss de Faria, Gabriel. Brand Equity: Um estudo sobre a marca Apple. Rio de Janeiro, 2017. 40 páginas. Trabalho de Conclusão de Curso Departamento de Administração. Pontifícia Universidade Católica do Rio de Janeiro.

Este trabalho foi realizado com o objetivo entender o comportamento do consumidor em relação a atitudes de tomada de decisão diante de uma nova perspectiva sobre marcas a partir de critérios do conceito de brand equity, com foco na marca Apple. O método empregado foi o quantitativo por meio da aplicação de uma survey composta de uma adaptação da escala multidimensional de brand equity do consumidor desenvolvida por Yoo e Donthu (2001). A conclusão da pesquisa aponta as dimensões do brand equity relativas à qualidade percebida $\mathrm{e}$ lembrança de marca como mais relevantes para a tomada de decisão do consumidor. Estas dimensões se constroem através de um valor agregado à marca pela qualidade de seus produtos e serviços disponíveis para os consumidores e a manutenção desta relação a longo prazo.

Palavras chave: Brand Equity - Marketing - Marcas - Apple 


\begin{abstract}
Weiss de Faria, Gabriel. Brand Equity: Um estudo sobre a marca Apple. Rio de Janeiro, 2017. 40 páginas. Trabalho de Conclusão de Curso Departamento de Administração. Pontifícia Universidade Católica do Rio de Janeiro.
\end{abstract}

This study had the objective to understand the consumers behavior related to decisions made through a new perspective of brands by the concepts of the dimensions of brand equity focused on the brand Apple. The research was made through a quantitative survey which adapted the multidimensional brand equity consumer base scale developed by Yoo and Donthu (2001). The conclusion of the research points to the dimensions of perceived quality and brand memories as the most relevant to the decisions made by the consumers. These dimensions are built through the added value from the brand through the quality and maintenance of this long term relationship.

Keywords: Marketing - Brand Equity - Branding 


\section{Sumário}

1 O tema e o problema de estudo 9

1.1. Introdução ao tema e ao problema do estudo 9

$\begin{array}{ll}\text { 1.2. Objetivo do estudo } & 11\end{array}$

1.3. Objetivos intermediários do estudo 11

1.4. Delimitação e foco do estudo 12

$\begin{array}{ll}\text { 1.5. Justificativa e relevância do estudo } & 13\end{array}$

2. Referencial Teórico 14

$\begin{array}{ll}\text { 2.1. Marca } & 14\end{array}$

2.1.1. A Marca e o Produto 16

2.2. Brand Equity 16

2.3. Brand Equity com Base no Consumidor 20

3 Metodologia de Pesquisa 22

3.1. Método de pesquisa utilizado 22

3.2. Fontes de informação selecionadas para coleta de dados no estudo22

3.3. Procedimentos e instrumentos de coleta de dados 23

3.4. Formas de tratamento e análise dos dados 24

3.5. Limitações do Estudo 24

4 Resultados $\quad 25$

4.1.1. Composição da amostra 25

4.1.2. Resultados relacionados à qualidade percebida 26

4.1.3. Resultados relacionados ao conhecimento da marca 28

4.1.4. Resultados relacionados a associações à marca 29

4.1.5. Resultados relacionados à lealdade à marca 30

4.1.6. Resultados relacionados à vantagem competitiva 31

5 Conclusão 34

5.1. Sugestões e recomendações para novos estudos 35 
6. Referências Bibliográficas

7. Anexo 1 38 


\section{Índice de Figuras}

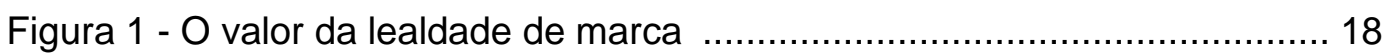

Figura 2 - Brand Equity segundo Aaker...................................................... 20

Figura 3 - Resumo das variáveis da pesquisa .............................................. 23

Figura 4 - Faixa etária da amostra de pesquisa............................................ 25

Figura 5 - Distribuição de renda da amostra de pesquisa............................... 26

Figura 6 - Respostas em relação à questão 1 ............................................. 27

Figura 7 - Respostas em relação à questão 2 .......................................... 27

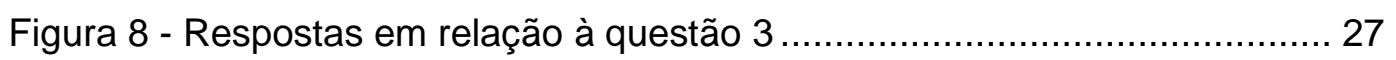

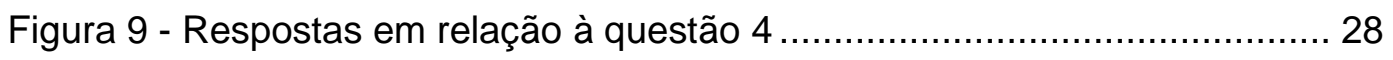

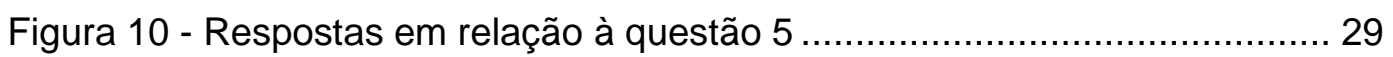

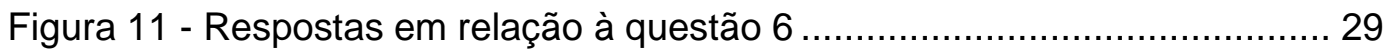

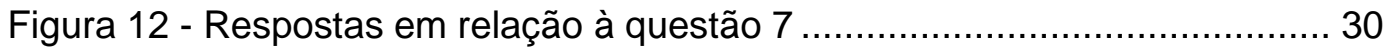

Figura 13 - Respostas em relação à questão 8 ............................................ 30

Figura 14 - Resultados em relação à questão 9 ............................................. 30

Figura 15 - Resultados em relação à questão 10 .......................................... 31

Figura 16 - Resultados em relação à questão 11 ........................................ 31

Figura 17 - Resultados em relação à questão 12 ......................................... 32

Figura 18 - Resultados em relação à questão 13 ......................................... 32

Figura 19 - Resultados em relação à questão 14 ............................................ 32 


\section{0 tema e o problema de estudo}

\subsection{Introdução ao tema e ao problema do estudo}

As marcas são utilizadas já há séculos por pessoas e empresas como uma forma de identificar um produto. Desta forma, cartas, manufaturas, obras de arte e diversos produtos são marcados com o intuito de se diferenciarem do resto a partir de uma logo, marca d'água ou impressões. A marca também tem como objetivo até hoje identificar produtos para seus clientes para que seja possível relacionar este produto com o fabricante estabelecendo um padrão ou selo de qualidade para o produto.

Segundo o site da Revista Exame (Disponível em <http://exame.abril.com.br/marketing/consumidores-brasileiros-sao-muitoenvolvidos-com-as-marcas/ >. Acesso em: 16 de maio de 2017) o Brasil é um dos países onde os consumidores mais se comprometem com as marcas, o relacionamento entre a marca e os consumidores vai além dos produtos e serviços de qualidade, pois os clientes desejam um diálogo permanente e relevante com as marcas que admiram. Com isso, o resultado financeiro deve ser visto não como um objetivo final, mas como uma conseqüência deste laço criado entre a marca e seus consumidores.

Para que uma relação entre a marca e um consumidor tenha uma longevidade é fundamental entendermos o comportamento do consumidor diante do que o mantém leal à marca e quais estratégias de marketing tomadas em relação ao brand equity da marca atraem ainda mais consumidores visando essa relação de longo prazo.

A partir de uma nova perspectiva de marca sobre a visão dos consumidores, o brand equity é um conceito utilizado para melhor entendermos o comportamento do consumidor e o valor agregado a um produto por uma marca, em que a perspectiva do cliente sobre a marca, as necessidades e desejos influenciam diretamente na estratégia de marketing adotada por uma marca (Keller e Machado, 2006). Assim, o que as diferentes marcas significam para o consumidor e seu conhecimento sobre elas podem trazer respostas quanto à tomada de decisão dos clientes ao executarem uma compra. 
O comportamento do consumidor pode ser influenciado por diversos fatores que têm impacto direto e indireto na sua tomada de decisão final quanto à escolha de um produto. Fatores sociais e culturais explicam muitas vezes os hábitos de consumo presentes e que fazem o consumidor optar por uma marca.

Muitas marcas buscam se posicionar diante deste comportamento e criam sua estratégia a partir disso a fim de criar valor agregado para seus clientes através de benefícios que possam trazer boas experiências para o seu públicoalvo e estar constantemente se renovando ao longo do tempo e das mudanças do mercado.

A imagem ganha uma importância muito grande para marca, pois a partir dela são feitas associações que podem ser positivas e negativas do ponto de vista do consumidor. A Apple é um exemplo de marca que estabelece sua imagem desde a sua fundação e além de ser uma empresa de tecnologia é bastante associada à criatividade, inovação, educação e a seu logo, reconhecido no mundo todo.

Com o estabelecimento desta imagem e as associações feitas a Apple consegue agregar valor a seus produtos de forma que estes são reconhecidos da mesma forma que a marca, um design limpo, criativo e de funcionalidade muito boa fazendo com que qualquer produto também tenha o mesmo padrão de qualidade sendo um grande diferencial na escolha do consumidor, que muitas vezes opta pela marca pela sua reputação mesmo que para isso deva investir um capital maior para seu consumo.

Brand equity baseado no cliente ocorre quando o consumidor tem alto grau de lembrança de marca e familiaridade com ela e retém na memória algumas associações fortes (Keller e Machado, 2006). O primeiro contato do consumidor com a marca é muito importante para um relacionamento entre ambos que possa durar anos e anos. Uma primeira experiência ruim obtida por um cliente pode encerrar o futuro entre essa relação. Para que isso não aconteça é importante que esta experiência seja positiva para os dois de forma que a lembrança que o cliente tenha sobre a marca seja positiva e, assim, este possa retornar a comprar produtos da marca e associá-la a uma boa lembrança. Segundo Kotler e Keller (2007) há três tipos de fatores que influenciam o processo de compra dos clientes: culturais, sociais e pessoais.

Com a evolução que a tecnologia vem tendo nos últimos anos a Apple, fundada em 1977, é uma das marcas mais fortes que se encontram no mercado. Por ser uma marca forte e bem posicionada ela possui vantagens em relação a outras, o que pode ser um diferencial na tomada de decisão do consumidor. 
A qualidade percebida, fidelidade dos clientes com a marca, margens maiores de lucro, oportunidades de extensão da marca e menor vulnerabilidade a crises torna a marca extremamente consolidada e mais estruturada para sobreviver a possíveis mudanças do mercado.

O brand equity com base no cliente tem o conhecimento da marca como chave para a criação de si mesmo (Keller e Machado, 2006). A memória é um elo que constantemente conecta as pessoas a experiências que tiveram anteriormente tendo a lembrança da marca, quando positiva, um importante fator para a retenção de clientes.

A partir disso a pesquisa busca saber: Com base no conceito de brand equity baseado no cliente, o quanto uma marca, no caso a Apple, agrega de valor a um produto?

\subsection{Objetivo do estudo}

O presente estudo tem como objetivo analisar quais fatores relacionados às dimensões do brand equity são mais relevantes para os consumidores e o quanto de valor a Apple agrega a seus produtos considerando tais dimensões.

\subsection{Objetivos intermediários do estudo}

Para o alcance do objetivo final proposto pelo estudo, temos como objetivos intermediários:

$\checkmark$ Entender o comportamento do consumidor diante de uma marca, no caso a Apple. Nesta etapa, o estudo busca apresentar o que leva o consumidor a optar por um produto da marca Apple diante do valor agregado a oferta do produto.

$\checkmark$ Identificar quais fatores influenciam a tomada de decisão do consumidor. Aqui analisamos quais fatores são mais relevantes para o consumidor diante da relação que ele possui com a marca Apple quando se está tomando uma decisão de compra e quais valores estão agregados à oferta da marca com base no seu brand equity. 
Investigar a tomada de decisão do consumidor a partir de associações feitas com base nos fatores influenciadores e entender quais desses fatores se tornam mais relevantes e o quanto de valor a marca Apple agrega para um produto.

\subsection{Delimitação e foco do estudo}

O estudo busca compreender o comportamento dos consumidores quanto a possíveis associações do cliente a marca Apple, visando entender como a marca agrega valor a seu produto. Muitas marcas possuem estratégias de marketing para posicionar a empresa quanto a uma forma de visão e filosofia o que muitas vezes atrai consumidores que compartilham dessa filosofia, o que vai além da simples funcionalidade de um produto. Um produto, quando identificado por uma marca, ganha valor ao modo que o padrão de qualidade de uma marca é estabelecido por essa identificação e, quando positiva, atrai novos clientes somente com a presença de um logo em um produto, o que pode ser considerado o caso da marca Apple.

Embora relevante, o estudo não busca abordar questões financeiras em relação a balanço e demonstrações de resultados da marca, mesmo que muitas vezes este fator possa influenciar a tomada de decisão de um cliente o foco do estudo está nas questões associadas a fatores intangíveis que possam influenciar a tomada de decisão do consumidor.

O conceito de brand equity faz uma avaliação subjetiva e intangível que os clientes fazem da marca atribuindo um valor muito além do objetivamente percebido, tendo como três impulsionadores: o conhecimento da marca, atitudes do cliente e percepção ética da marca. Desta forma o estudo busca verificar até que ponto um cliente está disposto a comprar um produto a partir do reflexo da imagem positiva criada por uma marca, do ponto de vista dos clientes e da percepção que estes possuem em relação à marca Apple.

O estudo leva em consideração uma amostra de residentes do Rio de Janeiro, de todas as classes sociais, homens e mulheres acima de 16 anos de idade. Assim, ele visa identificar quais razões levam o consumidor a optar por um produto da marca Apple e quais qualidades percebidas eles obtêm diante da marca, que fazem com que ainda que seja necessário investir uma quantidade 
de capital acima da média pelos produtos da marca, os clientes optem pela marca.

\subsection{Justificativa e relevância do estudo}

As informações que o estudo pretende produzir podem servir de exemplo para outras marcas, além da presente no estudo, que comercializam qualquer produto. Elas podem verificar em seus produtos o quanto de valor está agregado a ele, a partir de fatores que influenciam a tomada de decisão dos clientes e verificar se as estratégias de marketing que estão sendo feitas estão obtendo o resultado esperado por parte dos clientes e se suas perspectivas estão de acordo com a expectativa da marca.

Os resultados obtidos pelo estudo podem ser úteis para consultorias, empresas e profissionais de marketing, que têm a oportunidade de verificar quais fatores atualmente influenciam os compradores de um ponto de vista mais abstrato, relacionado ao intangível observado por estes consumidores tendo base no brand equity baseado no cliente.

Além disso, o estudo pode complementar estudos anteriores de brand equity buscando identificar qual a relevância do branding a um produto em relação a associações a marca em geral e valor agregado diante das categorias definidas pelo brand equity.

E por último a marca Apple, que pode ter o estudo como base relevante para verificar possíveis mudanças na forma como era observada no mercado e como é atualmente vista por parte de seus consumidores, entendendo quais fatores podem vir a influenciar mais seus clientes quanto à marca e ter uma vantagem competitiva. 


\section{Referencial Teórico}

Neste capítulo são apresentados e discutidos aspectos conceituais e estudos relacionados ao tema em investigação que servirá de base para a análise realizada. Para a elaboração do estudo foi necessária a definição dos conceitos utilizados visando clarear a análise quanto à marca e à abordagem feita a partir do brand equity.

Os conceitos buscarão analisar precisamente os fatores mais relevantes que impactam uma marca e a experiência de um consumidor na sua tomada de decisão de compra de produtos.

Esta seção será dividida em três partes e abordam, respectivamente, a questão do que é uma marca, a diferenciando de produto para que seja contextualizado o significado de valor dentro da perspectiva que o cliente tenha em relação a marca, o conceito de brand equity, que é utilizado no estudo com o objetivo de mensurar o valor da marca com base nos fatores que possam impactar no comportamento do consumidor.

E por fim o conceito de brand equity com base no cliente que busca definir quais fatores são mais relevantes para a tomada de decisão do cliente no processo de compra.

\subsection{Marca}

Segundo Aaker (1991), as marcas podem ser definidas como um nome diferenciado e/ou símbolo, logotipo, marca registrada, ou desenho destinado a identificar os bens ou serviços de um vendedor, ou grupo de vendedores, diferenciando esses bens e serviços dos concorrentes. Desta forma, é possível identificar a origem do produto e proteger tanto o consumidor quanto 0 fabricante, dos concorrentes que ofereçam produtos semelhantes.

Além de uma forma de identificação contra concorrentes, as marcas também são uma forma legal de proteger o fabricante quanto a cópias falsificadas do produto/serviço.

Segundo Aaker (1998), a marca é um ativo que através da sua facilidade no reconhecimento do fabricante, permite ao consumidor perceber uma qualidade no produto de uma empresa, sendo de tal forma reconhecida como 
uma extensão dos valores internos da corporação se tornando um diferencial próprio da empresa. Assim, da mesma forma que uma marca consegue distinguir seus parâmetros de qualidade diante dos concorrentes ela também pode servir como um indicador de riscos para o consumidor quanto à expectativa dele diante do produto de determinada marca.

Segundo Keller e Machado (2006), a criação de uma marca envolve a construção de estruturas mentais para ajudar os consumidores a organizar seu conhecimento sobre produtos e serviços de um modo que esclareça sua tomada de decisões e forneça valor para a empresa.

O processo de tomada de decisão dos consumidores é muitas vezes acelerado diante da presença de uma marca sendo identificada em um produto. A marca mostra a origem do fabricante, distribuidor, podendo gerar uma confiança maior diante de tal serviço/produto e conseqüentemente criando uma fidelização de um cliente com ela a partir do momento que esta é facilmente reconhecida por suas características próprias de atendimento e qualidade dos produtos/serviços.

Segundo Keller (2013), departamentos de marketing criam associações de favorecimento à opção por uma marca uma vez que associações feitas a marca convencem consumidores de que seus atributos são benéficos e satisfazem suas necessidades, gerando um julgamento positivo por parte dos clientes. Porém, nem todas as associações feitas à marca serão igualmente relevantes para todos os consumidores, da mesma forma que seus atributos e valores podem ter significados diferentes para cada consumidor ou levado em consideração em uma situação de compra.

Como exemplo podemos identificar associações feitas à marca Apple, na qual os consumidores associam tal marca à criatividade, inovação, seu logotipo(a maçã), tecnologia, Ipods, Iphones, e outros inúmeros produtos, características e atributos da marca. Com isso, podemos ver que a marca agrega valor ao produto através de sua presença o que, assim como as associações, gera uma expectativa de qualidade percebida pelo cliente, que por relacionar um produto à marca Apple, no caso, já possui uma expectativa de alto rendimento e alta qualidade de um produto, independente de qual seja.

Segundo Keller (2013), a essência do posicionamento das marcas é que as marcas possuem uma vantagem sustentável competitiva que dá ao consumidor uma razão convincente para que este compre a marca. Esta diferenciação pode ser feita através do direcionamento feito a partir de 
comparações feitas com concorrentes, forma mais utilizada nos Estados Unidos, ou demonstrando uma boa performance de seus atributos e seus benefícios.

\subsubsection{A Marca e o Produto}

Segundo Kotler e Keller (2011, pág. 366), "Produto é qualquer coisa que possa ser oferecida a um mercado para apreciação, aquisição, utilização ou consumo e que possa satisfazer uma necessidade ou um desejo. Assim o produto pode ser um bem físico, um serviço, uma loja de varejo, uma pessoa ou uma idéia".

Segundo Keller e Machado (2006), as marcas são um rótulo para o produto, ou seja, ela é uma forma de identificação do produto/serviço enquanto, ao mesmo tempo, o produto/serviço é o que dá significado à marca, o que ela pode fazer em termos de qualidades e atributos que se diferenciam dos demais concorrentes.

Segundo Aaker (1998), temos a diferenciação entre marca e produto diante da presença de um bem físico para que possa ser definido o produto enquanto a marca é uma identificação que acrescenta outras dimensões que o diferenciam de algum modo de outros produtos desenvolvidos para satisfazer a mesma necessidade podendo ser racionas e tangíveis, quando relacionadas ao desempenho de produto da marca, ou mais simbólicas, emocionais e intangíveis, quando considerada a representatividade da marca.

\subsection{Brand Equity}

Segundo Aaker (1991), o Brand Equity é um conjunto de ativos e passivos ligados a uma marca, seu nome e seu símbolo, que se somam ou se subtraem do valor proporcionado por um produto ou serviço para uma empresa e/ou para os consumidores dela.

A partir disso, o modelo de Aaker define Brand Equity como cinco categorias de ativos que se encontram como sua base, descritas a seguir:

\section{Lealdade à marca}

Segundo Aaker (2007) a lealdade de marca é definida pela probabilidade de um consumidor optar por mudar de marca ou não, especialmente caso a 
concorrente faça mudanças no preço ou nas características de um produto. O quanto um cliente escolhe por um produto/serviço de uma marca em relação aos concorrentes. Esta categoria é fundamental para uma marca, pois leva em consideração o tratamento ao consumidor, o quanto a marca atende as suas necessidades, medindo a satisfação do cliente e criando um custo de mudança, caso este cliente opte por mudar de marca. A lealdade de um cliente permite mais tempo para que sejam feitas melhorias, novas formas de satisfazer seus clientes e adotar novas estratégias no futuro, onde o aspecto de lealdade mais influencia o resultado das marcas.

Além disso, a lealdade dos clientes agrega valor à marca de diversas maneiras segundo Aaker (1998), tais como:

- Redução de custos de marketing - Uma vez que um cliente é leal à marca ele terá um grau maior de aceitação a mudanças executadas pela marca, ou seja, não há necessidade de gastos para que este continue optando pela marca. Enquanto isso os gastos para conquistar novos consumidores ou reconquistá-los são maiores, pois os clientes leais à marca não estão procurando outras marcas, sendo portanto necessário um esforço adicional dos concorrentes para que este cliente talvez possa considerar uma nova marca.

- Alavancagem comercial - Canais de distribuição tendem a optar por uma marca que possui um alto grau de lealdade entre ela e seus consumidores, pois esperam que seus produtos sejam comprados pelos clientes.

- Atração de novos consumidores - A lealdade de marca faz com que os próprios consumidores sejam agentes que atraiam novos consumidores. Isso é muito positivo para a marca pois através desta lembrança de marca pode expandir o seu número de clientes leais a ela.

- Tempo maior para resposta à concorrência - Os clientes que são leais à marca estão mais resistentes a apelos feitos pelas marcas concorrentes, permitindo um tempo maior de resposta a ações da concorrência.

\section{Lembrança de marca}

Segundo Aaker (1991) o conhecimento do nome é a capacidade que um comprador potencial tem de reconhecer ou se recordar de uma marca como integrante de certa categoria de produtos.

Esta é uma forma de estabelecer o quanto a marca está inserida no públicoalvo e o quanto os consumidores conhecem a seu respeito o que pode ser de 
extrema importância para que esta marca seja sempre levada em consideração dentro das opções do cliente.

Isto pode ser um diferencial, pois uma marca lembrada cria um senso de familiaridade na relação entre a marca e o consumidor gerando uma simpatia o que pode motivá-lo em sua tomada de decisão, o fazendo mudar de marca e aumentando o marketshare de uma marca, principalmente quando consideramos produtos de baixo envolvimento, como podemos ver na figura abaixo:

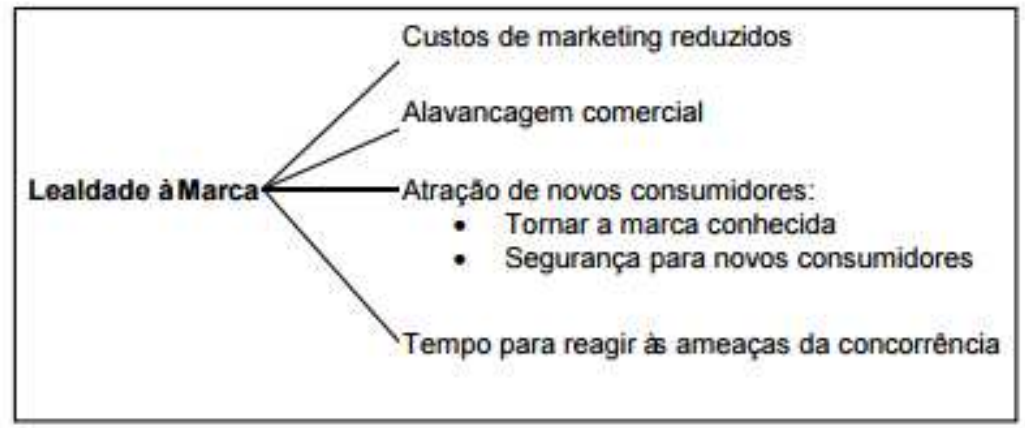

Figura 1 - O valor da lealdade de marca (Fonte: Aaker (1998))

\section{Qualidade percebida}

Segundo Aaker (1998), a qualidade percebida é a qualidade que um cliente percebe diante dos atributos e características de um produto de uma marca em relação aos seus concorrentes levando em consideração sentimentos, confiabilidade, desempenho e valor agregado além de especificações técnicas, a satisfação (expectativa x realidade) de acordo com a sua perspectiva e a atitude.

A percepção de qualidade do cliente pode ser um fator muito relevante na hora de escolher entre um produto/serviço a um concorrente, pois ele leva em consideração aquela marca que, para ele, possui uma qualidade superior às demais presentes no mercado o que pode ser também um diferencial para esta marca em relação aos seus concorrentes, principalmente se considerarmos extensões da marca para novos tipos de segmentações de produtos.

\section{Associações à marca em acréscimo à qualidade percebida}

Segundo Aaker (1998), as associações da marca podem ser feitas em relação a diversas características e atributos da marca, tais como: a experiência obtida ao se utilizar a marca, a imagem da marca, o sentimento em relação à 
marca, os benefícios que o cliente tem ao optar por um produto dela, o preço, utilidade, funcionalidade, o estilo de vida e o relacionamento do cliente com a marca.

Estas associações fazem com que os clientes assimilem diversas informações sobre a marca de forma direta em sua memória, sendo um fator também relativo à lembrança da marca.

O posicionamento da marca no mercado pode ser estabelecido por estas associações através da diferenciação dentro do mercado consumidor e acabam por se tornar a razão pela qual um consumidor opta por tal marca, sendo relevante também para uma possível extensão da marca para uma nova linha de produtos que também leve consigo as mesmas associações.

\section{Outros ativos do proprietário da marca}

Segundo Aaker (1998), esta categoria é a menos relevante como base para os conceitos de brand equity. Ela leva em consideração ativos tangíveis que agregam valor a marca, como registros, patentes, trademarks e relação com os canais de distribuição. Porém, tal categoria acrescenta um valor financeiro a marca, principalmente, considerando seus ativos circulantes e não circulantes e não os valores intangíveis relacionados a própria marca, questão abordada pelo estudo.

Abaixo, a figura 2 mostra um diagrama com as categorias de ativos da marca segundo Aaker (1998). 


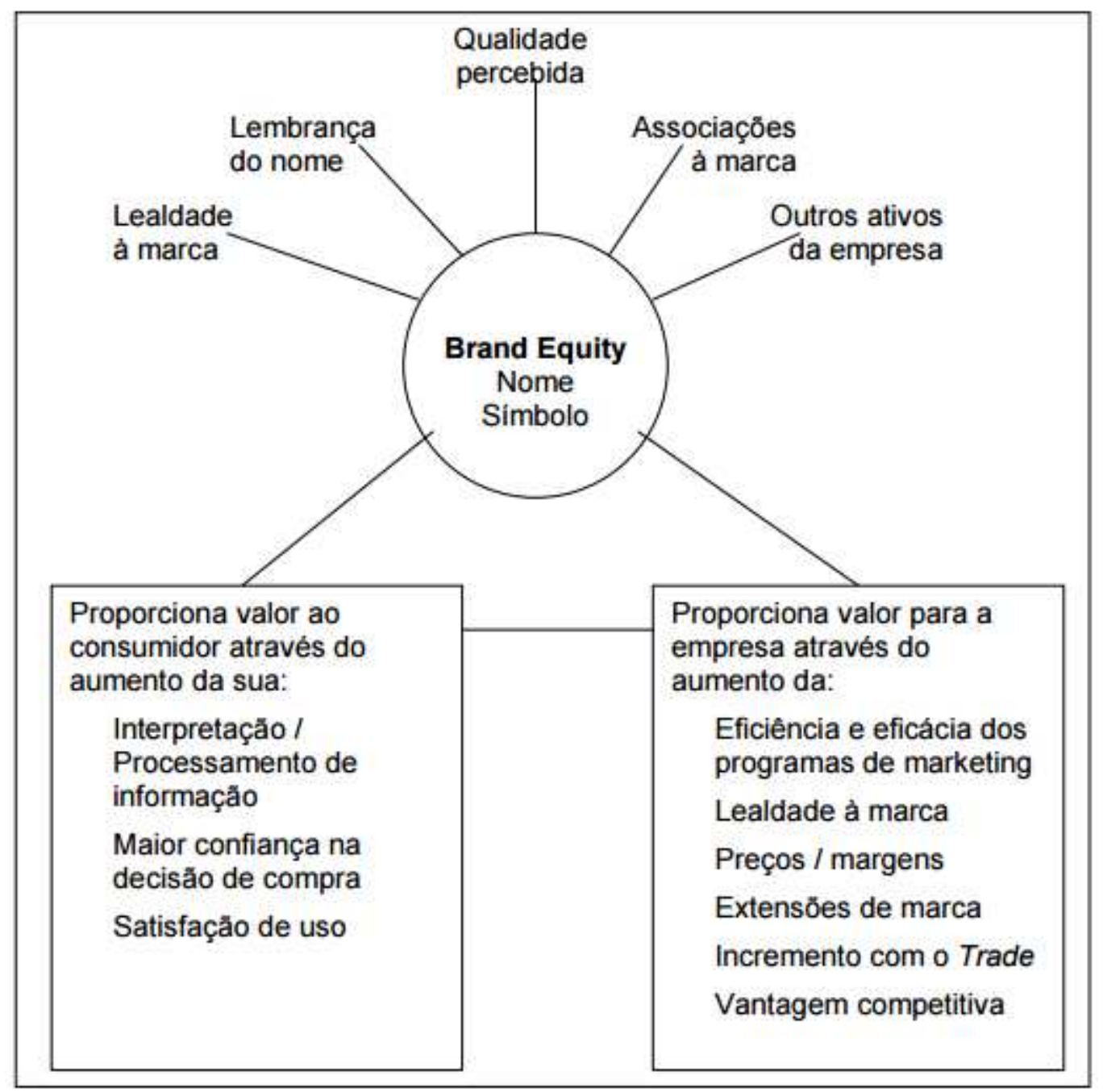

Figura 2 - Brand Equity segundo Aaker (Fonte: Aaker 1998)

\subsection{Brand Equity com Base no Consumidor}

Segundo Keller e Machado (2006), a definição de brand equity avalia os efeitos que a marca tem sobre determinado produto/serviço, ou seja, os diferentes resultados obtidos por um produto com uma marca em relação aos resultados que seriam obtidos sem que o produto tivesse uma marca identificada.

Segundo Keller e Machado (2006, pág.36), afirmam “a premissa básica do modelo de brand equity com base no consumidor é que a força da marca está no 
que os clientes aprenderam, sentiram, viram e ouviram sobre ela como resultado de suas experiências ao longo do tempo".

O modelo de brand equity com base no consumidor considera fundamental para o bom desempenho e conhecimento de uma marca a perspectiva do consumidor diante de suas qualidades e atributos. Este conhecimento que o consumidor possui sobre uma marca pode vir a ser o grande diferencial para a tomada de decisão final do cliente quando este vê sua necessidade sendo atendida por um produto de fato, ou seja, ele leva em consideração a primeira marca que vem em sua memória no momento da compra de um produto.

Segundo Keller e Machado (2006), o conhecimento da marca pode ser distinguido por dois fatores:

- Consciência de marca - A habilidade da marca de ser identificada no mercado através de uma memória que remete o cliente àquela marca. (Exemplo: Ao pensar em um telefone celular pensamos diretamente no Iphone.)

- Imagem da marca - Este conceito está ligado às associações que os consumidores fazem à marca que trazem uma memória em forma de lembrança para o consumidor no momento da compra. (Exemplo: Pensando em carne associa-se a marca Friboi.). 


\section{Metodologia de Pesquisa}

Este capítulo visa demonstrar a metodologia utilizada na presente pesquisa tem como objetivo entender o comportamento do consumidor diante da presença de uma marca, identificar quais fatores influenciam a tomada de decisão e validar a questão abordada pelo estudo sobre como uma marca, no caso a Apple, agrega valor a seus produtos de acordo com os conceitos de Brand Equity.

\subsection{Método de pesquisa utilizado}

Segundo Richardson (1989), a pesquisa quantitativa utiliza um método de quantificação de coleta de dados estatísticos para medir relações entre variáveis para investigações sobre características de fenômenos, tais como comportamentos e tomadas de decisão.

Segundo Gil (2008, pág. 17), "torna-se possível determinar em termos numéricos, a probabilidade de acerto de determinada conclusão, (...) a caracterizar-se por razoável grau de precisão, o que torna bastante aceito por parte dos pesquisadores com preocupações de ordem quantitativa."

A metodologia utilizada para analisar o comportamento do consumidor foi uma pesquisa de campo quantitativa, onde foi possível mensurar de forma objetiva as reações, atitudes e respostas frente a situações de forma a estabelecer relações entre os resultados obtidos e transformá-los em números para que possam ser classificados e analisados estatisticamente.

\subsection{Fontes de informação selecionadas para coleta de dados no estudo}

A pesquisa foi realizada sobre uma amostra total de 125 indivíduos, pois do total de 147 respostas recolhidas, 22 não foram considerados por não terem finalizado o questionário.

O questionário consistiu de 19 questões, as quais tinham como objetivo abordar questões relacionadas às dimensões de brand equity a fim de gerar dados para uma análise técnica quantitativa. A amostra consistiu em indivíduos 
do sexo masculino e feminino, com idade a partir de 16 anos, pertencentes a todas as classes sociais, com e sem renda pessoal, sendo estudantes de graduação, pós-graduação e doutorados, assim como profissionais de diversas áreas.

\subsection{Procedimentos e instrumentos de coleta de dados}

A escala utilizada foi uma versão adaptada do instrumento utilizado por Yoo e Donthu (2001) e conteve questões, dentre as quais abordavam perguntas de segmentação demográfica e relacionadas às dimensões do brand equity de qualidade percebida, conhecimento de marca, associações de marca, lealdade de marca e vantagem competitiva da marca Apple. Assim, a pesquisa tinha como objetivo definir quais características são mais relevantes para os consumidores na sua relação com uma marca e entender sua tomada de decisão diante das dimensões de brand equity.

A ferramenta utilizada para execução da pesquisa foi o Qualtrics Survey Software, o qual teve o link da pesquisa foi compartilhado via redes-sociais, emails para coleta de dados e pode ser separado de acordo com os tópicos relacionados às dimensões de brand equity e segmentações demográficas, conforme a Figura 3.

\begin{tabular}{|l|l|}
\hline \multicolumn{1}{|c|}{ Variável } & Itens \\
\hline Qualidade percebida & 3 questões \\
\hline Conhecimento de marca & 2 questões \\
\hline Associações de marca & 3 questões \\
\hline Lealdade de marca & 4 questões \\
\hline Vantagem Competitiva & 2 questões \\
\hline Segmentação demográfica & 5 questões \\
\hline
\end{tabular}

Figura 3 - Resumo das variáveis da pesquisa 
O questionário aplicado utilizou a escala Likert de cinco pontos, a fim de analisar a sensibilidade dos respondentes quanto às questões abordadas sobre as dimensões de brand equity, assim como simples repostas de "sim" ou "não" e escalas de relevância para melhor avaliação. O questionário completo pode ser visto no Anexo 1.

\subsection{Formas de tratamento e análise dos dados}

A pesquisa teve como objetivo identificar o comportamento dos consumidores em relação à tomada de decisão e atitudes frente a questões que abordam o brand equity de uma marca, em partícula a Apple. Foi feita uma análise quantitativa através das respostas obtidas, na qual mediu-se o percentual, buscando identificação de padrões e alinhavando os resultados à teoria descrita na revisão de literatura.

\subsection{Limitações do Estudo}

O resultado obtido através da pesquisa possui limitações inerentes ao método estatístico que aplica uma análise generalizada e "fria" dos números obtidos, não sendo possível levar em consideração fatores mais subjetivos quanto às questões abordadas.

Desta forma, também surge como uma limitação do estudo o fato de a análise feita não ter levado em consideração sentimentos da população da amostra em relação à Apple, fato relevante para o estudo de brand equity e que inviabiliza uma definição quanto ao sentimento que os clientes e consumidores possuem diante da marca.

Outra limitação encontra-se na população da amostra em que grande parte se limita àqueles que residem no Rio de Janeiro, não levando em consideração demais cidades. 


\section{Resultados}

Este capítulo visa demonstrar os resultados obtidos através da pesquisa analisando as dimensões de brand equity definidas por Aaker (1991) e Keller e Machado (2006) e as variáveis que influenciam o valor agregado pela marca Apple a seus produtos.

\subsubsection{Composição da amostra}

Daqueles que participaram do grupo da amostra, foi possível verificar que quanto ao gênero da população da amostra, 75 eram homens, o que corresponde a $60,0 \%$ e o restante - 50 mulheres, ou seja, $40,0 \%$.

Conforme a figura 4, a faixa etária da população se identificava como 103 indivíduos com idade entre 16 e 25 anos, o que corresponde a 82,40\% do total, $14,4 \%$ entre 26 e 35 anos e 2,4\% da amostra tinha idade acima de 36 anos.

\begin{tabular}{|c|c|c|}
\hline \multicolumn{1}{|c|}{ Faixa Etária } & Frequência & $\%$ \\
\hline Entre 16 e 25 anos & 103 & $82,4 \%$ \\
\hline Entre 26 e 35 anos & 18 & $14,4 \%$ \\
\hline Entre 36 e 45 anos & 1 & $0,8 \%$ \\
\hline Entre 46 e 55 anos & 0 & $0,0 \%$ \\
\hline Acima de 55 anos & 3 & 2,4 \\
\hline
\end{tabular}

Figura 4 - Faixa etária da amostra de pesquisa

Destes, 93 indivíduos tinham ensino superior incompleto, valor que se refere a $74,4 \%$ do total e sobre os demais. 16 concluíram o ensino médio e os outros 16 concluíram o ensino superior ou pós-graduação, valor que corresponde a $12,8 \%$ da amostra. 
A distribuição de renda do grupo foi estabelecida de forma que 34 respondentes confirmaram que não tinham renda, valor que representa 27,2\% da amostra; 27 tinha renda entre $R \$ 500$ e $R \$ 1500$, valor que significa $21,6 \%$ dos indivíduos, 16,8\% (21 indivíduos) possuem renda entre $\mathrm{R} \$ 1601$ e $\mathrm{R} \$ 3500$, $5,6 \%$ (7 indivíduos) com renda entre $R \$ 3501$ e $R \$ 7000$, e o restante, $29,37 \%$ (36 indivíduos), obtinham renda acima de $\mathrm{R} \$ 7000$, conforme a figura 5 :

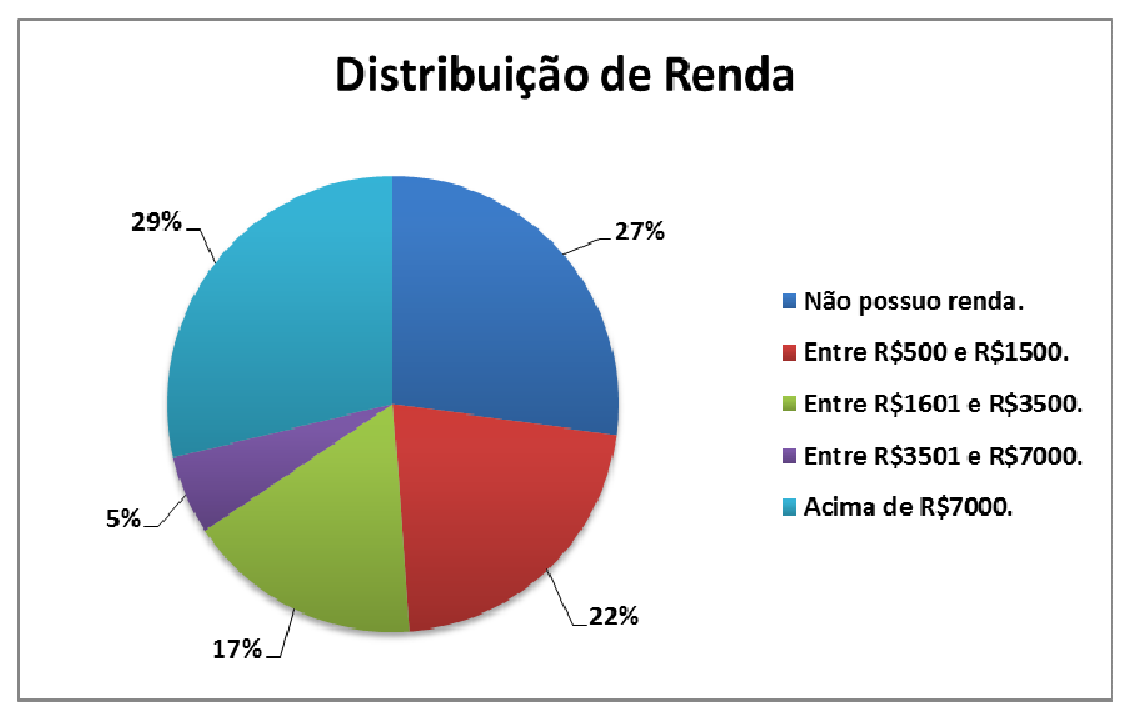

Figura 5 - Distribuição de renda da amostra de pesquisa

\subsubsection{Resultados relacionados à qualidade percebida}

Segundo Keller e Machado (2006), a qualidade percebida pode ser definida pela percepção que o cliente tem diante da qualidade geral atribuída às características do produto de uma marca e a percepção, que se tem diante das expectativas esperadas por ele em relação ao produto quando o mesmo é comparado aos demais concorrentes.

Desta forma, podemos observar que $91,2 \%$ já tiveram uma experiência anterior comprando ou utilizando algum produto da marca Apple enquanto 8,8\% nunca tiveram. Destes, 65,6\% tiveram sua expectativa alcançada e 21,6\% tiveram suas expectativas superadas pelos produtos da Apple. Isso mostra que a marca Apple agrega valor por meio de seu brand equity através da entrega ao consumidor daquilo que é prometido, pois a expectativa do cliente é medida de 
acordo com o que a própria marca atribui de característica a seus produtos em relação às necessidades a serem atendidas por parte do consumidor.

A seguir, nas figuras 6, 7 e 8 podemos verificar questões abordadas com relação à dimensão de qualidade percebida e as respostas obtidas:

\begin{tabular}{|c|c|c|}
\hline \multicolumn{3}{|c|}{$\begin{array}{c}\text { Q1 - Você já comprou/usou algum } \\
\text { produto da marca Apple? }\end{array}$} \\
\hline Respostas & Frequência & $\%$ \\
\hline Sim & 114 & $91,2 \%$ \\
\hline Não & 11 & $8,8 \%$ \\
\hline
\end{tabular}

Figura 6 - Respostas em relação à questão 1

\begin{tabular}{|c|c|c|}
\hline $\begin{array}{c}\text { Q2- O produto que você comprou/usou da marca Apple } \\
\text { atendeu as suas expectativas? }\end{array}$ \\
\hline Respostas & Frequência & $\%$ \\
\hline Deixou muito a desejar & 1 & $0,8 \%$ \\
\hline Deixou a desejar & 8 & $6,4 \%$ \\
\hline Neutro & 7 & $5,6 \%$ \\
\hline Atendeu as minhas expectativas & 82 & $65,6 \%$ \\
\hline Superou as minhas expectativas & 27 & $21,6 \%$ \\
\hline
\end{tabular}

Figura 7 - Respostas em relação à questão 2

\begin{tabular}{|c|c|c|}
\hline $\begin{array}{c}\text { Q3- Qual a sua expectativa em relação a um produto } \\
\text { da marca Apple em termos de qualidade? }\end{array}$ \\
\hline Respostas & Frequência & $\%$ \\
\hline Muito baixa qualidade & 0 & $0,0 \%$ \\
\hline Baixa qualidade & 0 & $0,0 \%$ \\
\hline Neutro & 7 & $5,6 \%$ \\
\hline Boa qualidade & 43 & $34,4 \%$ \\
\hline Muito boa qualidade & 75 & $60,0 \%$ \\
\hline
\end{tabular}

Figura 8 - Respostas em relação à questão 3

A partir das respostas obtidas podemos observar que $94,4 \%$ dos respondentes têm uma alta expectativa quanto à qualidade dos produtos da Apple, os considerando bons ou muito bons e $34 \%$ consideram a qualidade do produto o atributo que mais agrega valor a marca. 


\subsubsection{Resultados relacionados ao conhecimento da marca}

Segundo Keller (1993), o conhecimento de marca pode ser definido como uma característica que leva em consideração a reação que os consumidores têm diante dos componentes do mix de marketing da marca e das associações feitas por ele em relação à marca.

Este conceito pode ser reforçado pelos componentes definidos por Keller e Machado (2006) conforme abordado no referencial teórico: lembrança de marca e imagem de marca.

Desta forma, através das respostas de pesquisa podemos verificar que $86,4 \%$ dos respondentes têm uma recordação boa ou muito boa da Apple, demonstrando o valor agregado à marca quanto à experiência obtida entre ela e seus consumidores/clientes, enquanto $6,4 \%$ não possuem uma lembrança em relação à marca e $7,2 \%$ possuem uma lembrança ruim em relação a experiências anteriores.

Além disso, podemos verificar que, em sua maioria, os respondentes consideram a marca com um preço alto $(37,6 \%)$ ou muito alto $(62,4 \%)$, o que demonstra que os preços da Apple podem ser considerados uma diferenciação quando comparado aos demais produtos dos concorrentes. Porém, como vimos na resposta da primeira questão, mesmo a Apple atribuindo um preço diferenciado a seus produtos, ela consegue agregar valor a este preço uma vez que $91,2 \%$ dos entrevistados já usaram ou compraram um produto da marca.

Podemos verificar nas figuras 9 e 10 as perguntas e respostas adquiridas através da coleta de dados:

\begin{tabular}{|l|c|c|}
\hline \multicolumn{3}{|c|}{$\begin{array}{l}\text { Q4- Em relação a experiências anteriores com a Apple, } \\
\text { qual a lembrança que você tem em relação à marca? }\end{array}$} \\
\hline Respostas & Frequência & $\%$ \\
\hline Lembrança muito ruim & 0 & $0,0 \%$ \\
\hline Lembrança ruim & 9 & $7,2 \%$ \\
\hline Não tenho lembrança & 8 & $6,4 \%$ \\
\hline Tenho lembrança boa & 76 & $60,8 \%$ \\
\hline Tenho lembrança muito boa & 32 & $25,6 \%$ \\
\hline
\end{tabular}

Figura 9 - Respostas em relação à questão 4 


\begin{tabular}{|c|c|c|}
\hline \multicolumn{3}{|c|}{ Q5- Como você considera o preço dos produtos da } \\
Apple?
\end{tabular}

Figura 10 - Respostas em relação à questão 5

\subsubsection{Resultados relacionados a associações à marca}

Segundo Keller e Machado (2006), as associações de marca podem ser definidas como informações guardadas na memória dos consumidores que possam gerar significado à marca para os clientes.

Através da pesquisa foi possível contabilizar que 96,8\% dos entrevistados conseguem identificar a marca Apple entre as demais concorrentes do mercado e $59,2 \%$ dos respondentes conhecem bem a marca, enquanto $39,2 \%$ conhecem a marca de forma mediana e 3,2\% dizem não conhecer bem a marca.

Além disso, ao perguntar a respeito da lembrança que os indivíduos respondentes do questionário sobre a dificuldade de lembrança da marca Apple, todos responderam que não tinham tal dificuldade, ou seja, a marca Apple é uma marca fácil de ser lembrada pelos clientes e clientes potenciais, o que demonstra a presença da mesma no mercado e na memória de seus consumidores.

Abaixo, podemos visualizar nas figuras 11, 12 e 13 a seguir, as perguntas realizadas e os números de respostas obtidas através do questionário:

\begin{tabular}{|l|c|c|}
\hline \multicolumn{3}{|c|}{$\begin{array}{c}\text { Q6- Você consegue identificar a marca Apple entre } \\
\text { outras marcas concorrentes? }\end{array}$} \\
\hline Respostas & Frequência & $\%$ \\
\hline Sim & 121 & $96,8 \%$ \\
\hline Não & 4 & $3,2 \%$ \\
\hline
\end{tabular}

Figura 11 - Respostas em relação à questão 6 


\begin{tabular}{|l|c|c|}
\hline \multicolumn{3}{|c|}{ Q7- Você conhece bem a marca Apple? } \\
\hline Respostas & Frequência & $\%$ \\
\hline Sim & 74 & $59,2 \%$ \\
\hline Médio & 49 & $39,2 \%$ \\
\hline Não & 2 & $1,6 \%$ \\
\hline
\end{tabular}

Figura 12 - Respostas em relação à questão 7

\begin{tabular}{|l|c|c|}
\hline \multicolumn{3}{|c|}{ Q8- Você tem dificuldade de lembrar-se da marca } \\
Apple?
\end{tabular}

Figura 13 - Respostas em relação à questão 8

\subsubsection{Resultados relacionados à lealdade à marca}

Segundo Aaker (1998), a lealdade à marca é definida pelo cliente que continua a comprar uma certa marca, mesmo existindo concorrentes no mercado, que tenham diferentes preços e características até mesmo superiores de produtos e serviços. Isso gera uma fidelização muito grande na relação entre as partes envolvidas, cliente e marca, o que vêm a agregar valor pelo brand equity criado pela marca, considerando suas definições.

Desta forma, considerando as respostas obtidas pela coleta de dados podemos verificar que $40 \%$ dos respondentes se consideram leais à marca Apple, ou seja, 50 respondentes optam somente por produtos da Apple, considerando os mercados em que esta está inserida. Além disso, 48,8\% consideram a Apple a primeira opção de compra de produtos e $23,2 \%$ só compram produtos da Apple enquanto $51,2 \%$ não a consideram primeira opção de compra, mesmo que possam vir a comprá-la como uma opção viável.

A seguir, nas figuras 14, 15 e 16 podemos observar as perguntas utilizadas sobre a dimensão de lealdade de marca e as respostas obtidas:

\begin{tabular}{|l|c|c|}
\hline \multicolumn{3}{|c|}{ Q9- Você se considera leal à marca Apple? } \\
\hline Respostas & Frequência & \% \\
\hline Sim & 50 & $40,0 \%$ \\
\hline Não & 75 & $60,0 \%$ \\
\hline
\end{tabular}

Figura 14 - Resultados em relação à questão 9 


\begin{tabular}{|l|c|c|}
\hline \multicolumn{3}{|c|}{ Q10- A marca Apple é sua primeira opção de compra? } \\
\hline Respostas & Frequência & $\mathbf{\%}$ \\
\hline Sim & 61 & $48,8 \%$ \\
\hline Não & 64 & $51,2 \%$ \\
\hline
\end{tabular}

Figura 15 - Resultados em relação à questão 10

\begin{tabular}{|l|c|c|}
\hline \multicolumn{3}{|c|}{ Q11- Se a marca Apple está disponível na loja, você só } \\
compra ela?
\end{tabular}

Figura 16 - Resultados em relação à questão 11

\subsubsection{Resultados relacionados à vantagem competitiva}

A partir da pesquisa podemos ver que $0,8 \%$ dos respondentes, ao ser questionados sobre sua tomada de decisão quanto à marca escolhida em relação a um produto, não leva em consideração qual marca comprará enquanto $65,6 \%$ leva em consideração diversas marcas quando vai comprar algum produto. Além disso, $1,6 \%$ só compra o produto se for da Apple, $28,8 \%$ têm a Apple como primeira opção em caso de compra e 3,2\% considera outra marca específica, concorrente da Apple, em consideração na hora da compra.

De acordo com a coleta de dados realizada foi possível verificar que comparando um produto de um mesmo segmento da Apple com as demais concorrentes $37,6 \%$ dos respondentes escolheriam pela marca Apple, enquanto $7,2 \%$ optariam por um concorrente. Porém, 55,2\% dos entrevistados escolheriam pela opção que traria o melhor custo-benefício, independente da marca do produto.

Abaixo, seguem as figuras 17 e 18 correspondentes às perguntas realizadas e respostas relacionadas à dimensão de vantagem competitiva: 


\begin{tabular}{|l|c|c|}
\hline \multicolumn{3}{|c|}{ Q12- Quando você vai comprar um produto, você: } \\
\hline Respostas & Frequência & $\%$ \\
\hline Não se importa com a marca & 1 & $0,8 \%$ \\
\hline Considera diversas marcas & 82 & $65,6 \%$ \\
\hline Considera uma marca específica & 4 & $3,2 \%$ \\
\hline A primeira opção é a Apple & 36 & $28,8 \%$ \\
\hline Só compra se for Apple & 2 & $1,6 \%$ \\
\hline
\end{tabular}

Figura 17 - Resultados em relação à questão 12

\begin{tabular}{|c|c|c|}
\hline \multicolumn{3}{|c|}{$\begin{array}{l}\text { Q13- Comparando a Apple com as demais concorrentes do mercado, qual a opção } \\
\text { abaixo você escolheria comparando o mesmo produto da Apple com as demais } \\
\text { concorrentes: }\end{array}$} \\
\hline Respostas & Frequência & $\%$ \\
\hline Escolheria pela marca Apple & 47 & $37,6 \%$ \\
\hline Escolheria algum concorrente & 9 & $7,2 \%$ \\
\hline Escolheria o melhor custo-benefício, independente da marca & 69 & $55,2 \%$ \\
\hline
\end{tabular}

Figura 18 - Resultados em relação à questão 13

Ao analisar fatores que mais agregam valor à marca Apple, podemos ver que o resultado obtido leva em consideração diversas opiniões diferentes quanto à ordem que estes fatores atuam agregando valor à marca. A seguir, podemos observar na figura 19 as respostas do questionário mencionado:

\begin{tabular}{|c|c|c|c|c|c|c|c|c|c|c|c|c|c|c|c|c|}
\hline \multicolumn{17}{|c|}{$\begin{array}{l}\text { Q14- Enumere de } 1 \text { a } 8 \text { quais das características abaixo são as que mais agregam valor em relação a um } \\
\text { produto da Apple: }\end{array}$} \\
\hline \multirow{2}{*}{$\begin{array}{c}\text { Posição } \\
\text { Respostas }\end{array}$} & \multicolumn{2}{|c|}{1} & \multicolumn{2}{|c|}{2} & \multicolumn{2}{|c|}{3} & \multicolumn{2}{|c|}{4} & \multicolumn{2}{|c|}{5} & \multicolumn{2}{|c|}{6} & \multicolumn{2}{|c|}{7} & \multicolumn{2}{|c|}{8} \\
\hline & $\%$ & Freq. & $\%$ & Freq. & $\%$ & Freq. & $\%$ & Freq. & $\%$ & Freq. & $\%$ & Freq. & $\%$ & Freq. & $\%$ & Freq. \\
\hline $\begin{array}{l}1 \text { - A presença da logo no } \\
\text { produto }\end{array}$ & $4,8 \%$ & 6 & $8,0 \%$ & 10 & $2,4 \%$ & 3 & $3,2 \%$ & 4 & $11,2 \%$ & 14 & $16,8 \%$ & 21 & $29,6 \%$ & 37 & $24,0 \%$ & 30 \\
\hline $\begin{array}{l}2 \text { - A qualidade dos } \\
\text { produtos }\end{array}$ & $47,2 \%$ & 59 & $21,6 \%$ & 27 & $12,8 \%$ & 16 & $8,0 \%$ & 10 & $2,4 \%$ & 3 & $3,2 \%$ & 4 & $1,6 \%$ & 2 & $1,6 \%$ & 2 \\
\hline $\begin{array}{l}3 \text { - Como sou visto pela } \\
\text { sociedade usando o } \\
\text { produto }\end{array}$ & $4,8 \%$ & 6 & $3,2 \%$ & 4 & $6,4 \%$ & 8 & $0,8 \%$ & 1 & $3,2 \%$ & 4 & $11,2 \%$ & 14 & $33,6 \%$ & 42 & $33,6 \%$ & 42 \\
\hline $\begin{array}{l}4-0 \text { atendimento aos } \\
\text { clientes }\end{array}$ & $4,8 \%$ & 6 & $7,2 \%$ & 9 & $8,8 \%$ & 11 & $20,8 \%$ & 26 & $26,4 \%$ & 33 & $16,8 \%$ & 21 & $6,4 \%$ & 8 & $7,2 \%$ & 9 \\
\hline $\begin{array}{l}5 \text { - A funcionalidade dos } \\
\text { produtos }\end{array}$ & $16,0 \%$ & 20 & $27,2 \%$ & 34 & $22,4 \%$ & 28 & $12,0 \%$ & 15 & $12,8 \%$ & 16 & $4,0 \%$ & 5 & $1,6 \%$ & 2 & $0,8 \%$ & 1 \\
\hline 6 - A inovação dos produtos & $5,6 \%$ & 7 & $12,0 \%$ & 15 & $17,6 \%$ & 22 & $24,8 \%$ & 31 & $18,4 \%$ & 23 & $14,4 \%$ & 18 & $3,2 \%$ & 4 & $2,4 \%$ & 3 \\
\hline 7 - O preço dos produtos & $4,0 \%$ & 5 & $6,4 \%$ & 8 & $4,8 \%$ & 6 & $5,6 \%$ & 7 & $8,0 \%$ & 10 & $27,2 \%$ & 34 & $18,4 \%$ & 23 & $24,0 \%$ & 30 \\
\hline 8 - A confiança na marca & $11,2 \%$ & 14 & $12,8 \%$ & 16 & $21,6 \%$ & 27 & $23,2 \%$ & 29 & $16,0 \%$ & 20 & $6,4 \%$ & 8 & $4,0 \%$ & 5 & $4,8 \%$ & 6 \\
\hline
\end{tabular}

Figura 19 - Resultados em relação à questão 14 
Analisando o quadro de respostas da Figura 19 podemos observar que daqueles que participaram da pesquisa $47,2 \%$ consideraram a qualidade dos produtos como o fator que mais agrega valor aos produtos da Apple, dado seu nível de excelência na produção de seus produtos, sendo esta a característica mais relevante presente na pesquisa. Em segundo lugar, a funcionalidade de seus produtos, escolhida por $27,2 \%$ dos respondentes, é o item o qual foi considerado segundo mais relevante em relação às características presentes nos produtos da Apple, enquanto a confiança na marca pode ser considerada a terceira característica que mais agrega valor em relação a marca e seus produtos, sendo escolhida esta opção por $21,6 \%$ dos entrevistados.

A seguir, a inovação obtida nos produtos é uma vantagem competitiva a qual foi considerada a quarta mais importante por $24,8 \%$ dos indivíduos que responderam o questionário, em termos de valor agregado. Ao ser levado em consideração a característica atendimento aos clientes, parte apreciável de $26,4 \%$ considerou tal característica como a $5^{\circ}$ que mais agrega valor à Apple, a qual é uma marca que caracteriza seu atendimento como uma extensão dos produtos.

Em sexto lugar, o preço dos produtos também foi considerado por $27,2 \%$ dos participantes como um item que agrega valor à marca. Este foi um fator que chamou a atenção, uma vez que considerando o custo-benefício da marca, dado que anteriormente $62,4 \%$ destes consideraram os preços da Apple como caros em relação aos concorrentes, este ainda é um fator que difere a marca das demais.

Analisando o status social que se apresenta para os respondentes em relação à utilização da marca Apple, 33,6\% destes consideraram o status social como penúltimo colocado, dentre os itens abordados, numa escala de relevância e valor agregado aos produtos da Apple.

Por último, ao analisarmos a simples presença da logo da Apple em seus produtos, $24,0 \%$ dos entrevistados consideram esta a característica que menos agrega valor à marca Apple e seus produtos mesmo que esta seja a marca visual da empresa e, conforme visto em questões abordadas anteriormente, $100 \%$ dos respondentes lembram-se da Apple e 96,8\% conseguem identifica-la diante das demais concorrentes. 


\section{Conclusão}

O presente estudo tem como objetivo analisar quais fatores relacionados às dimensões do brand equity são mais relevantes para os consumidores e o quanto de valor a Apple agrega a seus produtos considerando tais dimensões.

A partir disso podemos observar através do estudo que o brand equity de uma marca, segundo Aaker (1998), leva em consideração cinco categorias que podem vir a agregar valor um produto/serviço, sendo eles: a qualidade percebida, lealdade de marca, conhecimento de marca (lembrança de marca), associações de marca e ativos. Estas cinco categorias conjuntas definem o brand equity de uma marca, nos permitindo analisar quais destas dimensões se tornam as mais relevantes e influenciam mais os consumidores na tomada de decisão de suas compras.

A pesquisa realizada levou em consideração todos os mercados em que a Apple está inserida. Desta forma, foi possível analisar diante da metodologia utilizada e seu formato adaptado, que uma marca pode agregar muito valor aos produtos de forma que a relação entre o preço e o valor agregado pela marca não sejam considerados um fator definitivo para uma tomada de decisão, mas sim a qualidade de seu produto/serviço, a manutenção da relação que há com os clientes e consumidores, de forma que seja construída uma lembrança positiva em relação à marca para estes clientes/consumidores.

Este conhecimento de marca, que é construído ao longo dos anos, pode ser um fator também diferencial e pode gerar uma lealdade muito forte entre um cliente e uma marca. Isso pode ser fundamental, pois quanto maior o esforço que um consumidor tem que fazer para mudar a marca a qual ele utiliza, maior a lealdade que ele tem diante de uma marca.

A qualidade percebida pelos consumidores, segundo a pesquisa, foi a dimensão de brand equity que teve maior relevância para a população da amostra, dentre as apresentadas pelo estudo. Isso demonstra que, para a população da amostra, a percepção dos clientes em relação à qualidade que uma marca apresenta em seus produtos e serviços é um fator primordial para sua tomada de decisão. 


\subsection{Sugestões e recomendações para novos estudos}

Como recomendação pode-se fazer o uso de uma análise contábil e financeira de uma marca, possibilitando trazer com uma finalidade objetiva, numérica e mais concreta da importância e relevância dos conceitos apresentados pelo brand equity.

Como uma segunda sugestão, pode-se fazer uma análise de outras marcas que estejam inseridas em outros segmentos de produtos, podendo fazer uma análise do brand equity para casos de produtos/serviços diferentes do apresentado no estudo.

Por último recomendo que o estudo sobre brand equity possa se estender para além de apenas marcas e produtos, mas estudos de brand equity que abordem partidos políticos e pessoas, podendo tornar possível fazer uma análise quanto aos valores agregados a estes. 


\section{Referências Bibliográficas}

AAKER, D. A. Brand Equity gerenciando o valor da marca. São Paulo, Negócio Editora, 1998.

AAKER, D. A. Managing Brand equity: Capitalizing on the Value of a Brand Name, New York Free Press, 1991.

GIL, A. C. Métodos e técnicas de pesquisa social. São Paulo: Editora Atlas, 2008 .

KELLER, L. K.; MACHADO, M. Gestão estratégica de marcas. Pearson Education: Empresa Cidadã, 2006.

KELLER, L. K. Strategic Brand Management: Building, Measuring, and Managing Brand Equity. Pearson Education: Always Learning, 2013.

KELLER, L. K. Conceptualizing, Measuring, and Managing Customer-Based Brand Equity, Journal of Marketing, 1993.

Revista Exame. Consumidores brasileiros são muito envolvidos com as marcas 2016. Rio de Janeiro, 2016. Disponível em:< http://exame.abril.com.br/marketing/consumidores-brasileiros-sao-muitoenvolvidos-com-as-marcas/ >. Acesso em: 16 de maio. 2017.

RICHARDSON, R. J. Pesquisa social: Métodos e Técnicas. São Paulo: Editora Atlas, 1989

YOO, B.; DONTHU, N. Journal of Business Research. Developing and validating a multidimensional consumer-based brand equity scale, 2001. 


\section{Anexo 1}

\section{Pesquisa}

Este questionário busca analisar como uma marca, no caso a Apple, agrega valor a seus produtos de acordo com os conceitos Brand Equity. A partir disso, considerando mercados em que a Apple está inserida, por favor, responda o questionário abaixo para que possa ser realizada a pesquisa (obs: As respostas serão mantidas em sigilo.).

(Questão sobre experiência do consumidor)

1) Você já comprou/usou algum produto da marca Apple?

( ) Não ( ) Sim

(Qualidade Percebida)

2) O produto que você comprou/usou da marca Apple atendeu as suas expectativas?

1- Deixou muito a desejar 2- deixou a desejar 3- Neutro 4- Atendeu minhas expectativas 5 - Superou minhas expectativas

3) Qual a sua expectativa em relação a um produto da marca Apple em termos de qualidade?

1- Muito baixa qualidade2- Baixa qualidade 3- Neutro 4-Boa qualidade 5Muito boa qualidade

(Conhecimento de Marca)

4) Em relação a experiências anteriores com a Apple, qual a lembrança que você tem em relação à marca?

1- Lembrança muito ruim 2-Lembrança ruim 3-Não lembro 4-Lembrança boa 5Lembrança muito boa

5) Você considera os preços dos produtos da Apple:

1- Muito Baixo 2- Baixo 3- Médio 4- Alto 5-Muito alto 
(Associações à marca)

6) Você consegue identificar a marca Apple entre outras marcas concorrentes?
( ) Não ( ) Sim

7) Você conhece bem a marca Apple?

( ) Não ( ) Mais ou menos ( ) Sim

8) Você tem dificuldade de lembrar da marca Apple?

( ) Não ( ) Sim

(Lealdade à marca)

9) Você se considera leal à marca Apple?

( ) Não ( ) Sim

10) A marca Apple é sua primeira opção de compra?

( ) Não ( ) Sim

11) Se a marca Apple está disponível na loja, você só compra ela?

( ) Não ( ) Sim

(Vantagem Competitiva)

12) Quando você vai comprar um produto, você:

1 - Não se importa com a marca 2- Considera diversas marcas 3 - Considera uma marca especifica4- A primeira opção é a Apple 5- Só compra se for da Apple

13) Comparando a Apple com as demais concorrentes do mercado, qual a opção abaixo você escolheria comparando o mesmo produto da Apple com as demais concorrentes:

1 - Escolheria pela marca Apple.

2- Escolheria por algum concorrente.

3- Escolheria o melhor custo-benefício, independente da marca.

4- Na dúvida escolheria pela Apple.

1- Não escolheria a marca Apple.

14) Enumere de 1 a 8 quais das características abaixo são as que mais agregam valor em relação a um produto da Apple: 

( ) A presença da logo no produto.
() A qualidade dos produtos.
( ) Como sou visto perante a sociedade usando o produto.
( ) $\mathrm{O}$ atendimento aos clientes.
( ) A funcionalidade dos produtos.
( ) A inovação dos produtos.
( ) O preço do produto.
( ) A confiança na marca.
(Dados demográficos)

15) Qual a sua faixa de renda mensal?

( ) Não possuo renda.

( ) Entre $R \$ 500$ e $R \$ 1500$.

( ) Entre $R \$ 1601$ e $R \$ 3500$.

( ) Entre $R \$ 3501$ e $R \$ 7000$.

( ) Acima de $R \$ 7000$.

\section{6) Qual a sua faixa etária?}

( ) Entre 16 e 25 ( ) Entre 26 e 35 ( ) Entre 36 e 45 ( ) 46 e 55 ( ) 56 ou maior

17) Sexo:

( ) $\mathrm{M}() \mathrm{F}$

18) Qual é o seu grau de escolaridade?
( ) 1 Grau completo.
( ) 2o Grau completo.
( ) 3 Grau completo.
( ) Superior incompleto.
( ) Superior completo.
( ) Pós-Graduação.
( ) Doutorado.

19) Profissão:

Obrigado pela participação. 